\title{
ELEMENTOS DE TRANSFORMAÇÕES CULTURAIS DAS QUADRILHAS JUNINAS NOS FESTIVAIS FOLCLÓRICOS DE BOA VISTA-RORAIMA (2001-2011)
}

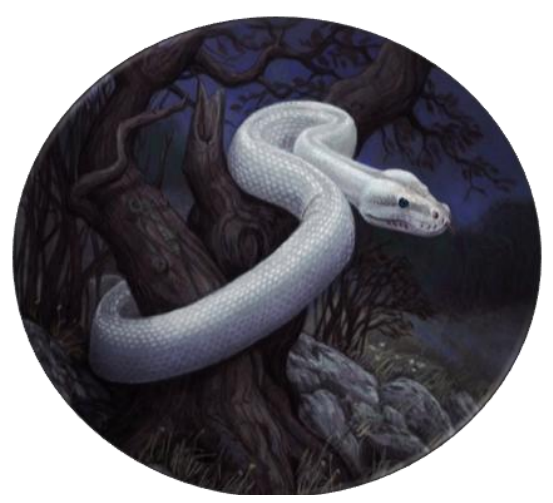

Teresa Kátia Alves de Albuquerque

Sérgio Ivan Gil Braga²

\section{Resumo}

O presente trabalho propõe-se a analisar os elementos responsáveis pelas transformações culturais verificadas nas apresentações dos grupos folclóricos de quadrilhas juninas na cidade de Boa Vista, capital do Estado de Roraima, no período de 2001 a 2011, resultado da Dissertação de Mestrado defendida em junho de 2013, intitulada: “As quadrilhas Juninas e suas transformações culturais nos festivais folclóricos de Boa Vista - Roraima (2001-2011)". A metodologia inclui levantamento bibliográfico, pesquisa de campo e registros etnográficos dos múltiplos aspectos culturais envolvidos no evento, além de entrevistas semiestruturadas, visando fornecer subsídios para o entendimento do processo de transformação dos grupos que participam nos concursos de quadrilhas juninas.

Palavras-chave: Quadrilhas juninas. Cultura Popular. Boa Vista/Roraima.

\begin{abstract}
The present work proposes to analyze the elements responsible for the cultural transformations verified in the presentations of the folklore groups of Juninas gangs in the city of Boa Vista, capital of the State of Roraima, in the period from 2001 to 2011, result
\end{abstract}

1 Mestre em Sociedade e Cultura na Amazônia (UFAM) Professora do Centro de Educação da Universidade Federal de Roraima. E-mail: teresa.katia@gmail.com

2 Doutor em Antropologia Social. Professor do Departamento de Antropologia do Programa de Pós-Graduação em Antropologia Social, do Programa de Pós-Graduação em Sociedade e Cultura na Amazônia e do Programa de Pós-Graduação em Sociologia (UFAM). E-mail: sigbraga@ufam.edu.br 
of the Master's Dissertation defended in June of 2013, titled: "The Juninas gangs and their cultural transformations in the folk festivals of Boa Vista - Roraima (2001-2011)". The methodology includes a bibliographical survey, field research and ethnographic records of the multiple cultural aspects involved in the event, as well as semi-structured interviews, aiming to provide support for understanding the process of transformation of the groups participating in the June gang contests.

Keywords: Juninas gangs. Popular culture. Boa Vista / Roraima.

\section{Introdução}

Os concursos de quadrilhas juninas em Boa Vista iniciaram em 1980, mas adquiriram maior visibilidade a partir de 2001, quando passaram a receber recursos financeiros do Governo Estadual e da Prefeitura Municipal. De modo geral, observa-se que práticas culturais tradicionais festivas ao longo da década estudada tiveram modificações no que se refere a uma dimensão espetacularizada do evento, que pode ser visualizada em múltiplos aspectos, como na dança, na música, na vestimenta e na alegoria (ALBUQUERQUE, 2013).

Em dez anos (de 2001 a 2011) as quadrilhas sofreram mudanças em relação a alguns aspectos, como: os brincantes se caracterizam conforme o tema da dança; coreografia, os grupos são obrigados a executarem, no mínimo, quatro passos tradicionais nos concursos promovidos pelos órgãos públicos, os brincantes precisam ter um ótimo desempenho na dança, porque estão sendo avaliados e competindo com outros grupos; na música, é necessário que cada grupo apresente letra inédita e tema a ser desenvolvido durante a evolução da quadrilha, e no processo de organização social, os grupos de quadrilhas se tornaram empresas, possuindo Cadastro Nacional Pessoa Jurídica (CNPJ), e se filiaram a instituições que os representam legalmente, ou seja, a Federação Roraimense das Quadrilhas Juninas (FERQUAJ) e a Liga das Quadrilhas 
Juninas e Grupos Folclóricos de Roraima (LIQUAJUR) ${ }^{3}$. Observam-se também transformações na formação dos grupos, na dança, no figurino, na música e melodia.

Nos dias atuais, cada grupo apresenta uma temática que é desenvolvida durante a dança, são incorporados personagens que inspiram uma música, "homenageiam” artistas da televisão, meio ambiente, de revistas em quadrinhos, as tecnologias, pontos geográficos, festejos natalinos, a Copa do Mundo, entre outros. De acordo com Silva, P., (2009, p. 07), parecem passar por um processo de amadurecimento artístico, aproximando-se da profissionalização: "deixando de lado a figura do tabaréu ${ }^{4}$ desdentado, feio e sujo, as quadrilhas incorporam personagens (Lampião, Maria Bonita, Cangaceiro) e adotam indumentárias luxuosas”.

As mudanças foram gradativas, iniciando a partir de 2001 nos festivais folclóricos, com o apoio financeiro do poder público (Estado e Município) e na dimensão de espetáculo que adquiriram nos eventos. Após dez anos, verificam-se transformações culturais significativas nas apresentações de quadrilhas, elementos tradicionais estão sendo suprimidos e novos elementos foram inseridos.

Para efeito de análise da pesquisa realizada por Albuquerque (2013), foram selecionados três grupos folclóricos, considerando pioneirismo, relevância social e transformações verificadas em múltiplos aspectos desses grupos, no período definido para estudo.

Cada grupo estudado possui uma característica especial, que determinou o motivo da seleção para participar da pesquisa: a quadrilha Zé Monteirão foi uma das pioneiras no processo de inovação, inserindo tema, alegorias e mudando estilo na roupagem dos brincantes; a quadrilha Eita

\footnotetext{
${ }^{3}$ A Associação das Quadrilhas Juninas de Roraima e Grupos Folclóricos (AQUAJUR) foi criada em 2001 e se transformou em Liga das Quadrilhas Juninas e Grupos Folclóricos de Roraima no mês de julho de 2011.

${ }^{4}$ De acordo com Cascudo (1972), tabaréu é um nome dado ao habitante que mora no campo, também chamado de matuto e roceiro.
} 
Junino continuou com essa "revolução" quadrilheira, destaca-se por apresentar grandes espetáculos; e a Forrozão Caipira, é a quadrilha mais antiga que as duas anteriores, inovou nas apresentações no final da década de 1990, mas foi superada pelas outras, mesmo assim, compete com os grandes grupos.

A metodologia foi constituída de levantamento bibliográfico, pesquisa de campo e registro etnográfico de múltiplos aspectos culturais envolvidos no evento. Foi adotada a abordagem da pesquisa qualitativa e os dados que foram coletados serão apresentados de forma descritiva.

\section{A cultura popular numa perspectiva dinâmica}

A vida de um grupo social passa por várias transformações de ordem temporal e histórica, algumas mudam mais lentamente e outras mais rapidamente, dependem do espaço e do tempo histórico em que surgiram. $\mathrm{O}$ estudo destes fatores nos faz entender o que seja a cultura popular, considerado por Gullar (2006) um fenômeno novo na vida brasileira. O sentido do "fenômeno novo", para Ortiz (2006), é entendido como a desvinculação com o caráter apenas conservador, que lhe era atribuído anteriormente, permanecendo esta característica para o folclore, entendida como manifestações culturais de cunho tradicional e a cultura popular, sendo dinâmica e sujeita a transformações. Ferreti (2007, p. 03) entende a expressão cultura popular como “[...] uma forma mais moderna de designar o folclore".

O enfoque que é dado às transformações da cultura popular analisada por Magnani (2003, p. 26) que, por outro ângulo, nos faz compreender que muitos pesquisadores que se dizem defensores, são concomitantemente resistentes às transformações: "a mudança de uma vestimenta, a substituição de um instrumento ou adaptação de um antigo 
costume são vistos como sintomas da progressiva diluição das tradições populares". Para este autor,

Mais relevante que lamentar a perda de uma suposta autenticidade, no entanto, é tentar analisar as crenças, costumes, festas, valores e formas de entretenimento na forma em que se apresentam hoje, pois a cultura, mais que uma soma de produtos, é o processo de sua constante recriação, num espaço socialmente determinado (MAGNANI, 2003, p. 26).

De acordo com Canclini (2011), o folclore na modernidade acompanhou as transformações das tecnologias e o avanço das comunicações, assim como se percebe no crescimento da difusão das culturas tradicionais, com a promoção das indústrias fonográficas, aos festivais de dança, ampla divulgação por meio da mídia radiofônica e televisiva das músicas locais em escala nacional e internacional.

Assim, as quadrilhas juninas, enquanto grupos folclóricos vêm mantendo sua tradição nos festejos juninos, nos passos da dança e na música, entre outras, assim como cultura popular que, além da tradição, vêm assumindo uma postura renovada e aberta as transformações em suas múltiplas interações com as questões socioculturais.

Cavalcante e Gonçalves (2009, p. 112) entendem que as inovações individuais que foram realizadas e responderam às exigências da coletividade, tornam-se elementos da obra folclórica, tendo em vista que foram aceitos e integrados, na concepção modernista, os processos culturais assim compreendidos como folclore “[...] são dotados de extraordinário dinamismo, por isso mesmo, de forte capacidade de permanecer ao longo do tempo [...]".

Portanto, torna-se importante entender o significado de cultura numa perspectiva antropológica, tendo em vista que as transformações se processam no segmento da cultura popular em Boa Vista, mais especificamente nas quadrilhas juninas. Neste sentido, Braga (2007a, p. 55) 
menciona que "[...] desde a segunda metade do século XIX, o conceito de cultura tem recebido diferentes acepções”, sendo que é interpretado como um fator dinâmico e complexo.

Canclini (2011) enfatiza que as transformações culturais sofreram influências das novas tecnologias - responsáveis em promover também criatividade e inovação -, e das mudanças no processo de produção, meios de comunicação, além da expansão do espaço urbano. Venturelli (2004, p. 11) entende que o termo "novas tecnologias" relacionadas à arte, trata-se da “[...] fotografia, o cinema e o vídeo e, por 'tecnologias contemporâneas', as computacionais". Assim, a cultura pode ser vista como um conjunto de atividades e modos de agir, costumes e instruções de uma sociedade.

Para designar a mescla das culturas ou a variedade dos objetos híbridos, Burke (2009, p. 39) utiliza-se da terminologia “crioulização", além de discutir em sua obra Hibridismo Cultural, outras variedades de nomenclaturas, assim afirma: "estarei, portanto, discutindo as idéias de empréstimo, hibridismo, caldeirão cultural, ensopadinho cultural e finalmente, tradução cultural e crioulização". Então, de todas estas designações, a mais utilizada como modelo de mesclas culturais foi crioulização, modelo linguístico estendido a outras formas de culturas.

\section{A quadrilha em Boa Vista}

O interesse em pesquisar sobre "quadrilha junina" de Boa Vista, vai ao encontro de minha experiência vivida como brincante e por ter participado de apresentações em festivais folclóricos promovidos pela instituição onde estudava no ano de 1976, ou seja, a Escola Estadual Monteiro Lobato ${ }^{\mathrm{i} 5}$ na cidade de Boa Vista, capital do então "Território

\footnotetext{
${ }^{5}$ A Escola Estadual Monteiro Lobato foi fundada em 10 de abril de 1949, está localizada na Rua Cecília Brasil, Bairro Centro.
} 
Federal de Roraima", hoje, Estado de Roraima, quando se dançava a quadrilha tradicional.

Neste período, a quadrilha era formada pelos estudantes e coordenada pela professora de Educação Física, que exercia múltiplas funções: coreógrafa, figurinista e marcadora ${ }^{6}$. Os casais de dançarinos eram formados por colegas de sala de aula das turmas de $5^{\mathrm{a}}$. e $6^{\mathrm{a}}$. Séries do Ensino Fundamental, na faixa etária de 11 e 12 anos. Os ensaios eram realizados no pátio e na quadra de esportes da própria escola após as aulas.

O grupo de quadrilha que se apresentava na festa junina da escola não tinha muito luxo, porém, eram admirados pelo público presente: familiares e comunidade local. O espaço da festa era enfeitado com bandeirinhas coloridas confeccionadas pelos próprios estudantes, que aproveitavam revistas antigas, cordão e cola para sua confecção e, depois de prontas, ornamentavam o local da festa. Naquele período, as quadrilhas escolares eram coordenadas pelos professores de Educação Física de cada escola.

$\mathrm{Na}$ época, a quadrilha junina seguia os padrões tradicionais com relação aos passos, da dança, coreografia, vestuário e músicas. Não havia cenários e nem adereços. Apenas as roupas das meninas, seguiam um padrão, ou seja, mesmos tecidos de $\operatorname{chita}^{7}$ bem estampadas e modelos idênticos, raríssimas quadrilheiras apresentavam-se com modelos diferentes. Os meninos se caracterizavam de "caipira": calças e camisas com remendos ${ }^{8}$, chapéu de palha na cabeça e maquiagem no rosto demonstrando barba e bigode (Figura 01).

\footnotetext{
${ }^{6}$ Em Roraima, o termo "marcador" utilizado no passado nas quadrilhas foi substituído por "animador".

${ }^{7}$ Chita é um tecido de baixo custo financeiro, estampado, muito utilizado no vestuário de quadrilhas.

${ }^{8}$ Remendos são panos pequenos que se usavam para decorar as roupas dos meninos que representavam o "matuto", relativo a quem vive no mato, na roça, ou caipira.
} 
Sobre as vestimentas dos brincantes de quadrilhas juninas, era típica do Brasil, de acordo com Freire, Rocha e Gomes (2011, p. 02), “o vestuário típico representava o povo da roça, as damas usavam vestidos longos, muito coloridos e cheios de bordados. Os homens vestiam camisas listradas ou xadrez, chapéu, lenço no pescoço, calça com remendos e chinelos" (Figura 01).
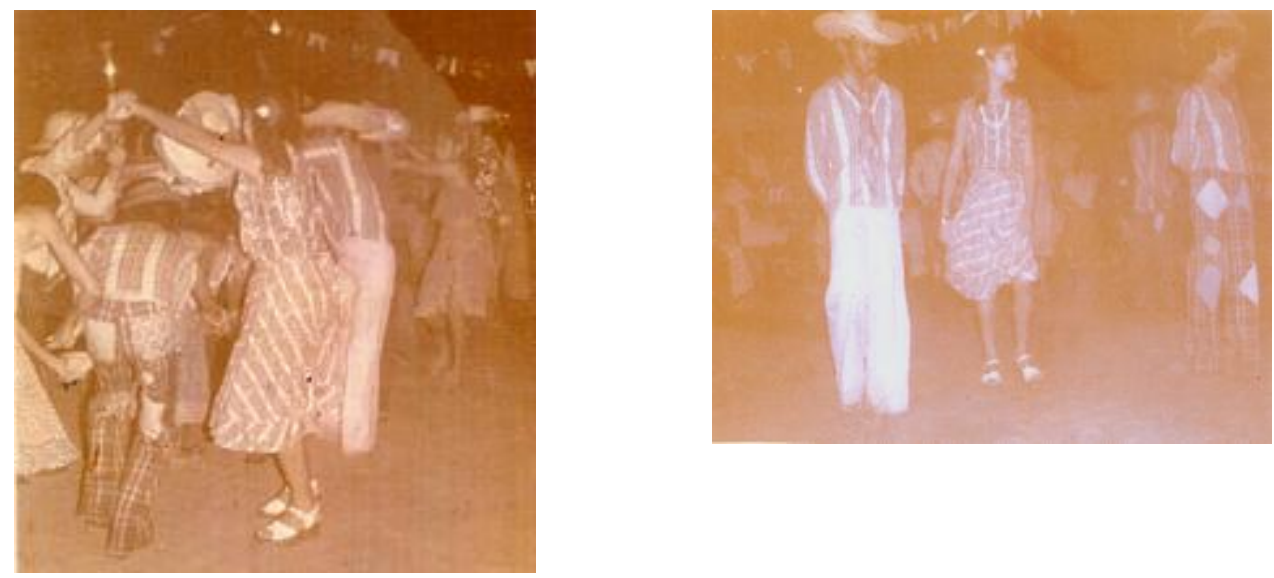

Figura 01: Brincantes de quadrilha junina incluindo a autora, na Escola Estadual Monteiro Lobato em 1976.

Fonte: ALBUQUERQUE, A. P. C. ${ }^{9}, 1976$.

A atração principal era a celebração do casamento, que durava aproximadamente quinze minutos. A dança da quadrilha era realizada para comemorar a celebração do casamento, os personagens da encenação eram: os noivos, o pai e a mãe da noiva, o padre e o policial. Eram escolhidos para representar o casal de noivos, os jovens mais humorísticos, com facilidade de desenvoltura e improvisação, que se comunicassem bem com o público, com o objetivo de chamar a atenção. O público se divertia com a desenvoltura dos noivos durante a representação teatral. Geralmente, os

\footnotetext{
${ }^{9}$ Autor da fotografia: o senhor Antônio de Pádua Castor de Albuquerque (in memorian), pai da pesquisadora.
} 
mesmos casal de jovens permaneciam por 3 (três) ou 4 (quatro) anos sendo os noivos da quadrilha.

Nos dias atuais, observa-se nova forma de se produzir quadrilha, desde a escolha do tema (temas infantis, de cunho social, histórico, cultural), na forma de apresentar abrangendo teatro, danças coreografadas, inserindo dentro das apresentações efeitos de iluminação com cenários de palco gigantescos e acabamentos perfeitos. Segundo a professora Maria Nancy Melo Figueiredo "as quadrilhas se inovaram de maneira tal que ela criou os passos próprios, foi se inovando, é uma dança que a gente não conhece mais aquela quadrilha".

\section{Dinâmica cultural: análise a partir das transformações de quadrilhas}

A análise dos fenômenos culturais se altera conforme a dinâmica de cada grupo. Para Durham (2004) a transformação cultural pode ocorrer no contexto da cultura de massa, como um processo de reelaboração dos produtos oferecidos ou impostos pela cultura industrial ou mesmo pelo Estado.

As mudanças se tornam visíveis a partir da valorização do passado ou da existência de padrões culturais tradicionais, e estes aspectos não podem ser excluídos na conjuntura atual. Para Durham (2004), a constatação da persistência desses padrões e da valorização do novo e do moderno é explicada na análise do processo de transformação social, considerando que "os padrões culturais sobrevivem na medida em que persistem as situações que lhes deram origem ou alteram seu significado para expressar novos problemas" (DURHAM, 2004, p. 230).

Outro aspecto observado por Durham (2004) na análise da dinâmica cultural, trata da necessidade de visualizá-la, não como produto, mas do modo que é produzida. Assim, o estudo possibilitou identificar os elementos que contribuíram nas mudanças e inovações dos grupos de 
quadrilhas juninas em Boa Vista no período de 2001 a 2011, a partir da análise do material coletado nas entrevistas, que podem ser por questões internas, quando ocorre por parte dos próprios grupos (aperfeiçoamento dos passos, formação de novos grupos, inserção de alegorias no tablado, aumento no número de brincantes), ou externas (patrocinadores, torcida organizada, a plateia)

Um dos elementos de renovação observado é a encenação apresentada pelos jovens atores na entrada, que são os próprios brincantes da quadrilha, na interpretação de uma história de acordo com o tema que faz parte do seu desenvolvimento. As caracterizações dos personagens são diversas, dependendo apenas do tema que será desenvolvido durante a quadrilha, como: indígenas, balloween, personagens do Maurício de Souza, Luiz Gonzaga, entre outros (Figuras 02 e 03). Além disso, observam-se em cena adereços e alegorias que identificam o tema.

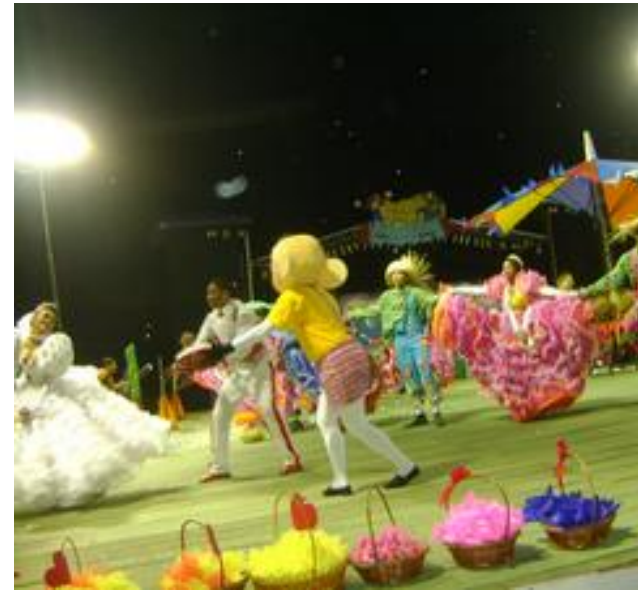

Figura 02: Quadrilha Forrozão Caipira em 2011. Fonte: ALBUQUERQUE, T. K. A., 2011.

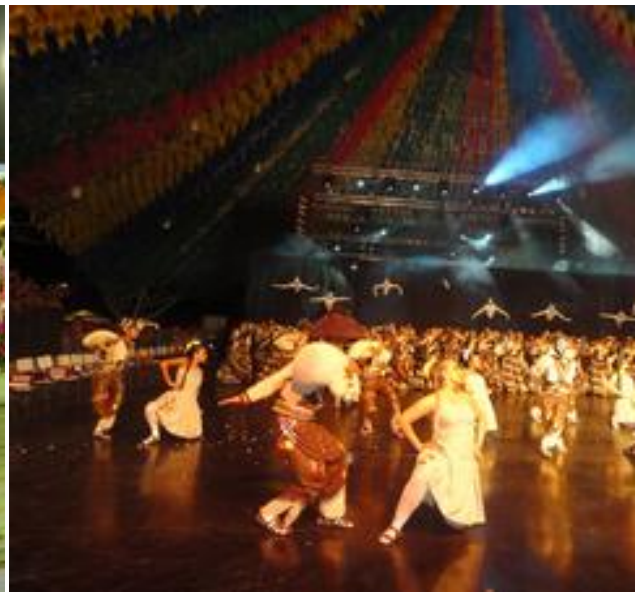

Figura 03: Quadrilha Eita Junino em 2012.

Fonte: ALBUQUERQUE, T. K. A., 2012.

Entre os elementos detectados nas quadrilhas, a figura do jovem adquiriu maior visibilidade, já que a maioria dos brincantes é de faixa etária entre 16 a 25 anos. De acordo com o que preconiza o Estatuto da Criança e do Adolescente (Lei no 8.069 de 13 de julho de 1990), abrange a categoria 
entre adolescentes (12 a 18 anos de idade) e adultos, com idade entre 19 a 59 anos de idade. Para o IBGE (2010), o jovem possui entre 15 a 24 anos de idade. Já para a Organização das Nações Unidas (ONU), a idade situada entre a infância e a adolescência e a adulta compreende a faixa etária entre 16 e 29 anos.

Portanto, sobre o perfil desse jovem, Barrientos-Parra (2004, p. 132) atribui como revolucionário capaz de lançar novas propostas, é bastante criador, objetiva a construção de uma sociedade melhor. No plano cultural, o jovem cria “[...] modismos e formas peculiares de comunicação. Renova a linguagem musical, as concepções artísticas, a ação política, a vida científica e desportiva [...]".

De modo geral, em Boa Vista há perfis bem definidos nos grupos de quadrilhas: uns que são produtores de brincantes e outros receptores. Para Erikson (1987, p. 244) isso reflete na ânsia de locomoção da juventude, que expressa "ir em frente" ou "andar atrás de alguma coisa". Para este autor, a juventude está sempre decidida a aprender, a testar extremos antes de decidir por um determinado rumo. Estes aspectos podem justificar a dinâmica dos brincantes nas quadrilhas juninas em Boa Vista, considerando a experiência do mesmo jovem em diferentes grupos, inclusive, no surgimento de novos grupos.

O elemento genealogia das quadrilhas juninas adquire relevância em termos quantitativos, já que passaram a participar de concursos um maior número de quadrilhas, e qualitativos devido à melhoria nas apresentações. Os criadores do novo grupo de quadrilha procuraram sempre aperfeiçoar o trabalho do que era feito anteriormente. Assim, para Canclini (2011), todas as artes se desenvolvem em relação a outras artes, em que estas mudanças fizeram com que os grupos perdessem a relação exclusiva com seu território ou grupo anterior e ganhassem com as novas práticas. Pode-se ratificar este fato no grupo de quadrilha Eita Junino, que se formou a partir da saída de alguns componentes que participavam de 
outro grupo, assim como a Zé Monteirão, que deixou de ser uma quadrilha escolar para se institucionalizar.

Todavia, nem sempre a criação de novos grupos ocorreu de forma pacífica, mas devido a conflitos internos, sobre este aspecto Velho (1977, p. 46) percebeu na sua pesquisa realizada num terreiro de umbanda do Rio de Janeiro, que os conflitos e incidentes seguiam o mesmo padrão de desenvolvimento, e “[...] as coisas não seguiam por acaso, mas era difícil a tarefa de analisar e entender como aconteciam".

Portanto, verifica-se que, quando há a divergência de pensamentos ou opiniões, gera conflitos. Porém, pude constatar, que os novos grupos formados esforçam-se para apresentarem melhores estruturas se for comparar com as que faziam parte anteriormente, no que se refere à coreografia, vestimentas, adereços, entre outros aspectos.

Por outro lado, a rivalidade entre os grupos de quadrilhas é visível apenas no período dos concursos por se tratar de uma competição, porque se unem em prol de uma causa própria, quando o assunto irá beneficiar a classe de quadrilheiros.

Constatei que os grupos inventaram e inseriram novos elementos e esse pioneirismo mostra a ousadia dos quadrilheiros jovens. Neste aspecto, a Zé Monteirão inseriu o uso tema, antes mesmo da obrigatoriedade em concursos. Além disso, mudou o vestuário masculino, com o uso de macacão, e utilizou renda, cetim e fitilho no vestuário feminino (Figuras 04 e 05). 


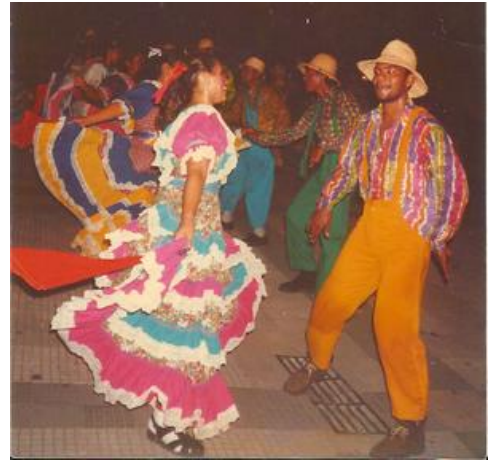

Figura 04: Quadrilha Zé Monteirão em 1997.

Fonte: Quadrilha Zé Monteirão, 1997.

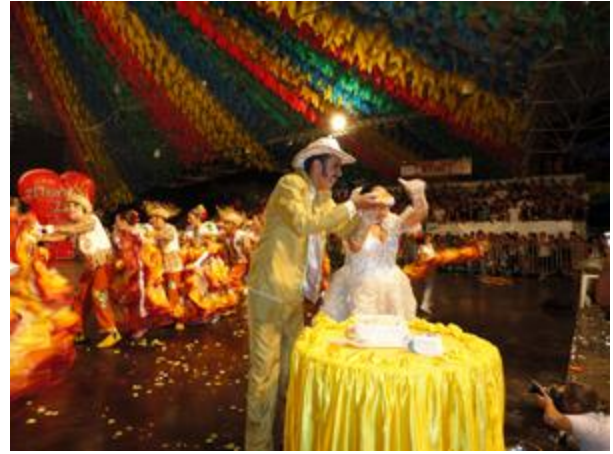

Figura 05: Quadrilha Zé Monteirão em 2012.

Fonte: Quadrilha Zé Monteirão, 2012.

Assim, a criatividade dos artistas torna-se relevante nos trabalhos de produção de alegorias, cenários, vestuários, entre outros, concomitantemente a necessidade de apresentarem novidades.

A interação que existe entre os brincantes e a plateia é um elemento de conquista por parte das quadrilhas. Este intercâmbio, quando se faz presente, resulta numa apresentação bem-sucedida, é a que inclui o ato de dançar e cantar simultaneamente, além de querer ser visto, admirado e fazer parte da brincadeira, é julgado pelo seu desempenho. Goffman (2009) entende que este público, enquanto plateia, respeita a atuação dos atores, neste caso, os brincantes, já que a interação entre eles trata-se de um diálogo entre duas equipes, e esta ação contribui para que o espetáculo seja de ambas as partes (Figura 06).

Numa produção, Chianca (2007) afirma que há o envolvimento em torno da quadrilha de uma vasta rede de especialistas, por exemplo: puxadores, costureiras, coreógrafos, músicos, iluminadores, dançarinos, entre outros. A relação deste elemento está ligada com a forma de organização administrativa do grupo (Figura 07). 


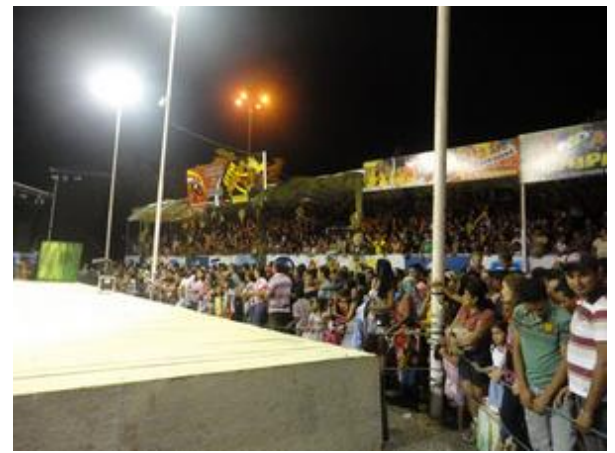

Figura 06: Visão parcial da plateia no festival municipal em 2011. Fonte: ALBUQUERQUE, T. K. A., 2011.

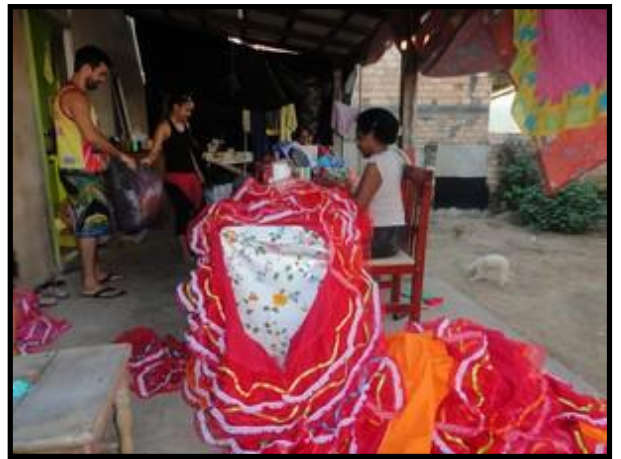

Figura 07: Costureiras contratadas pela Quadrilha Forrozão Caipira em 2011.

Fonte: ALBUQUERQUE, T. K. A., 2011.

A quadrilha Eita Junino conta com o apoio destes profissionais. São especialistas que participam do planejamento geral da equipe e possuem funções específicas.

Já a Forrozão Caipira planeja suas ações e a administração fica centrada apenas na família, ao passo que, amigos e ex-brincantes organizam a Zé Monteirão.

Com relação à gestão dos grupos, a familiar predomina em Boa Vista, assim como no Grupo Forrozão Caipira, desde a criação até os dias atuais, enfatizando que os brincantes são jovens de outras famílias. É a residência do fundador o local de concentração durante todo o processo de organização e produção do grupo. A Eita Junino foi criada por membros da mesma família e pessoas amigas, que tanto estão na diretoria como são brincantes. Já a Zé Monteirão, entre os grupos pesquisados, é a única que possui forma de administração diferenciada, foi formada por ex-brincantes e amigos da quadrilha quando deixou de fazer parte da Escola Estadual Monteiro Lobato.

Outro aspecto que deve ser citado refere-se ao ritmo em que os grupos evoluíram, foi o caso da quadrilha Zé Monteirão que introduziu o cenário no tablado no ano de 2001, uma homenagem ao escritor Monteiro 
Lobato, e foi superada por outros grupos, que sofisticaram no uso deste mesmo recurso, por exemplo, a quadrilha Eita Junino no ano de 2006, com o tema da Copa do Mundo, quando montou no tablado um campo de futebol, com traves e bandeiras. Inclusive, pode-se ressaltar que, apesar das críticas na época, as inovações trazidas com alegorias e vestimentas, em que as quadrilhas estavam gradativamente inserindo novos elementos, não descaracterizaram o que o público estava acostumado a se ver, os traços tradicionais permaneceram presentes na dança, nos passos ou nas roupas. De certa forma, essa quadrilha abriu caminhos pelo que se assiste atualmente em concursos, se for observado como se apresentavam antigamente para as apresentações de hoje, houve um salto no processo evolutivo.

É neste sentido que Cavalcante (2006) designa de espetáculo quando a festa desenvolve uma extraordinária sofisticação artística, assim como nos Bumbás de Parintins e nas Escolas de Samba do Rio de Janeiro e, no caso das quadrilhas, são as apresentações em concursos que demonstram esta característica. De acordo com Chianca (2007), são auxiliados pela criatividade dos artistas, expondo o luxo e a beleza, novos passos coreografados são acrescentados, dançarinos com roupas bem cortadas. Já Giffoni (1973) afirma que nas próprias indumentárias o gosto artístico e a cultura se revelam, além de ritmo, música, trabalhos manuais, entre outros.

O apoio financeiro recebido pelo poder público pode ter contribuído para a espetacularização das apresentações que se assiste nos dias atuais em concursos. Porém, os grupos também buscam patrocínios com empresas privadas na captação de recursos. Além disso, promovem eventos como: feijoadas, rifas, festas ou bingos. Um fato que poderia destacar é com relação às camisas personalizadas que os brincantes usam nos ensaios ou eventos, em que constam impressos logotipos e nomes de patrocinadores. 
Burke (2009) atribui ao avanço da tecnologia de comunicação como sendo principal aspecto pelas mudanças culturais. Assim, este é o elemento que os grupos possuem em comum, tanto Eita Junino, Forrozão Caipira e Zé Monteirão pesquisam informações sobre o tema na internet. Com a coleta do material, elaboram um projeto com as etapas do desenvolvimento do tema.

As misturas de elementos e contribuições oriundas de outros estados estão presentes nas quadrilhas de Boa Vista, seja no tema, na música, no vestuário, nas coreográficas, entre outros. Para Burke (2009), as culturas são heterogêneas, e as formas híbridas devem ser vistas como o resultado de encontros múltiplos, resultando na adição de novos elementos à mistura.

Para Chianca (2007) as quadrilhas juninas se tornaram um espetáculo à parte, bastante disputado e sempre atrai grande público para os festivais. Se os grupos de quadrilhas juninas continuassem apresentando apenas os passos tradicionais, talvez não tivessem tanta relevância como nos dias atuais, de forma que o processo evolutivo foi acompanhado por transformações culturais.

\section{Considerações Finais}

A mudança nas quadrilhas juninas em Boa Vista faz parte da própria dinâmica cultural, visto que em 2001, a produção e organização dos grupos se restringiam, em parte, às vestimentas e às coreografias mais simples do que se tem apresentado nos dias atuais. Não havia complementos como cenários, alegorias ou efeitos especiais.

Nos últimos anos, houve a necessidade da inserção de novas formas de produzir quadrilha. Neste sentido, um fato que se destaca é a estrutura organizacional, sendo que as quadrilhas devem estar filiadas a instituições que as representem legalmente, e que surgiram com o intuito de 
fortalecer o movimento junino, atendendo a novas regras. Estes fatores resultaram em ricas produções, não se dança apenas por diversão, agora há jurados e um público mais exigente e, consequentemente, as competições tornaram-se acirradas entre os quadrilheiros.

No entanto, pude constatar que o espaço festivo não acompanhou os grupos de quadrilhas, que evoluíram, tanto em quantidade de pares de brincantes que sobem no tablado assim como na inclusão de alegorias e adereços, além de maior participação do público que prestigia o evento a cada ano. Este espaço é o mesmo desde 2001, principalmente no arraial realizado na Praça do Centro Cívico, aspecto este já observado pela comunidade em geral.

E, quanto ao regulamento do concurso, é realizado em consonância com a equipe de coordenação da esfera pública e os quadrilheiros. Já a plateia, formada por familiares, amigos e simpatizantes, desempenha um trabalho de suma importância durante o concurso, tendo em vista que contribui, incentivando as quadrilhas que estão se apresentando. Pude constatar que o concurso de quadrilhas atrai o público ao evento, principalmente na apresentação daquelas que são do grupo especial.

Constatei os elementos que mostram as transformações culturais nas quadrilhas juninas ao longo de 10 anos (2001 a 2011), a saber: inovação das vestimentas dos brincantes, aumento no número de dançarinos preenchendo o tablado completo, aperfeiçoamento de passos, contratação de coreógrafos, inserção de alegorias e acessórios, organização administrativa e financeira mais sistemática, inclusão de tema e letra de músicas originais, regulamento do concurso renovado, concurso de Rei Matuto, para fazer parceria com a Rainha Caipira, competição mais acirrada; captação de recursos por patrocinadores de empresas privadas, ousadia e experimentação por parte dos jovens, buscando apresentar novidades. Este processo foi gradativo de acordo com as inovações que 
foram sendo inseridas pelos grupos, assim, foi adquirindo maior visibilidade nos concursos de quadrilhas patrocinados pelo poder público estadual e municipal.

Assim, percebi o quanto as quadrilhas juninas atingiram grandes proporções em termos de apresentação, de organização e dinâmica. Deixaram de ser festas escolares e adquiriram status de evento nos calendários estadual e municipal. Além disso, devido à própria estrutura interna, independente de concurso, são convidadas a se apresentarem em eventos locais e regionais, onde representam o estado de Roraima. Concluo que, todos esses elementos citados anteriormente, estão interligados nos grupos de quadrilhas e contribuíram para que atingissem esse patamar e resultou na sua transformação cultural.

Após estudo realizado, concluo apresentando os elementos que influenciaram nas transformações culturais das quadrilhas juninas de Boa Vista (RR).

Em primeiro lugar, a influência no modelo de festas do carnaval carioca: espetáculo, alegoria, vestimenta, luxo, desenvolvimento de um enredo que foi sendo adaptados ao contexto local.

Aliados a este processo, em segundo lugar, destaco a importância na definição de um tema, que tem compromisso com música, letra, coreografia e alegorias. Estes elementos estão integrados entre si e adquirem visibilidade nos quesitos de julgamento, enfatizando o Desenvolvimento do Tema, ou seja, se o que foi apresentado pela quadrilha estava adequado ao tema proposto durante a sua evolução.

Em terceiro lugar, a existência de quadrilhas produtoras e receptoras de brincantes é bem definida. No primeiro caso, um menor número de brincantes permite maior dedicação dos envolvidos. Já no segundo, se inclui os grupos formados por pessoas experientes.

Aponto em quarto lugar, a criação de novas quadrilhas associadas à disputa de um saber dito tradicional e inovador, haja vista a 
predominância de um público jovem responsável por este processo, que busca enfrentar desafios pelo novo, cria modismos e desenvolve trabalhos artísticos inovadores.

Por fim, no quinto lugar, percebi que, a relação com os órgãos oficiais não é representativa no que diz respeito à dependência artística e organizacional dos grupos, que mantêm sua autonomia e têm buscado recursos próprios. Há, inclusive, a ideia de um único festival oficial, que deve ser atendida ou não pelo estado e município, dependendo de prováveis interesses políticos por conta disso.

\section{Referências}

ALBUQUERQUE, Teresa Kátia Alves de. As quadrilhas juninas e suas transformações culturais nos festivais folclóricos em Boa Vista - Roraima (2001-2011). 2013. 154f. Dissertação (Mestrado em Sociedade e Cultura na Amazônia) Instituto de Ciências Humanas e Letras. Universidade Federal do Amazonas, Manaus.

BARRIENTOS-PARRA, Jorge. O Estatuto da Juventude: Instrumento para o desenvolvimento integral dos jovens. Brasília a. 41 n. 163 jul./set. 2004. Disponível em: <http://www.uje.com.br/estatutodajuventude/arquivos/EstatutodaJuvent udecomentado.pdf $>$. Acesso em: 01 mar. 2013.

BRAGA, Sérgio Ivan Gil Braga. Festas religiosas e populares na Amazônia: algumas cinsiderações sobre cultura popular. In: BRAGA, Sérgio Ivan Gil (Org.) Cultura popular, patrimônio imaterial e cidades. Manaus-AM: Editora da Universidade Federal do Amazonas, 2007a. 55 - 75 p.

BURKE, Peter. Hibridismo cultural. Tradução de Leila Souza Mendes. São Leopoldo-RS: Editora Unisinos, 2009. (Coleção Aldus, 18).

CANCLINI, Nestor Garcia. Culturas híbridas: estratégias para entrar e sair da modernidade. 4. ed. Tradução de Ana Regina Lessa e Heloísa Pezza Cintrão. São Paulo: Editora da Universidade de São Paulo, 2011. (Ensaios Latinoamericanos, 1).

CASCUDO, Luís Câmara. Dicionário do Folclore Brasileiro. 3. ed. Rio de Janeiro: INL, 1972. 
CAVALCANTE, Maria Laura Viveiros de Castro. Carnaval carioca: dos bastidores ao desfile. 3. ed. Rio de Janeiro: EdUFRJ, 2006. Resenha de: GONÇALVES, Renata de Sá. MANA 13(2): 579-588, 2007. Disponível em: $\quad<\quad$ http://www.scielo.br/scielo.php?pid=S010493132007000200014\&script=sci_arttext $>$. Acesso em: 04 jan. 2013.

CAVALCANTE, Maria Laura Viveiros de Castro; GONÇALVES, José Reginaldo Santos (Orgs.). As festas e os dias: ritos e sociabilidades festivas. Rio de Janeiro: Contra Capa, 2009.

CHIANCA, Luciana. Quando o campo está na cidade: migração, identidade e festa. 2007. Disponível em:

<http://redalyc.uaemex.mx/pdf/703/70310106.pdf>. Acesso em: 14 abr. 2011.

DURHAM, Ribeiro Eunice. A dinâmica da cultura: ensaios de antropologia. São Paulo: Cosac Naify, 2004.

ERIKSON, Erik H. Identidade: juventude e crise. Tradução de Álvaro Cabral. Rio de Janeiro: Editora Guanabara, 1987.

FERRETI, Sérgio Figueiredo. Dimensões da cultura: popular, erudita. Ciências Humanas em Revista - São Luís, V.5, n.2, dezembro 2007. Disponível em: $<$ http://www.nucleohumanidades.ufma.br/pastas/CHR/2007_2/sergio_f erretti_v5_n2.pdf>. Acesso em: 05 jan. 2013.

FREIRE, Bryza Marinho; ROCHA, Rayanne Rodrigues; GOMES, Ronisson Ribeiro. A transformação das quadrilhas juninas: uma bistória de resistência. RELEM - Revista Eletrônica Mutações, julho - dezembro, 2011. Cby Ufam/Icsez. Disponível em: <http://www.relem.info/edicoes/ed3/rep2.pdf>. Acesso em: 24 abr. 2012.

GIFFONI, Maria Amália Correa. A dança folclórica brasileira. São Paulo, 1973.

GOFFMAN, Erving. A representação do Eu na vida cotidiana. 17. ed. Tradução de Maria Célia Santos Raposo. Petrópolis, RJ: Vozes, 2009.

GULLAR, Ferreira. Cultura posta em questão: vanguarda e subdesenvolvimento. 2. ed. Rio de Janeiro: José Olympio, 2006.

IBGE-Instituto Brasileiro de Geografia e Estatística. Dados Roraima. 2010. Disponível em: <http://www.censo2010.ibge.gov.br>. Acesso em: 04 abr. 2012. 
MAGNANI, José Guilherme Cantor. Festa no pedaço: cultura popular e lazer na cidade. 3 ed. São Paulo: UNESP, 2003.

ORTIZ, Renato. Cultura brasileira e identidade nacional. 5. ed. São Paulo: Brasiliense, 2006.

SILVA, Paulo Rogério de Feitas; OLIVEIRA, Rafael da Silva (Orgs.). Roraima 20 anos: as geografias de um novo Estado. Boa Vista: Editora da UFRR, 2008.

VELHO, Yvonne Maggie Alves. Guerra de Orixá: um estudo de ritual e conflito. 2. ed. Rio de Janeiro: Zahar Editores, 1977.

VENTURELLI, Suzete. Arte: espaço_tempo,_imagem. Brasília: Editora Universidade de Brasília, 2004. 